\title{
ASSESSMENT METHODOLOGY FOR VOLATILE ORGANIC COMPOUNDS FROM LEACHATE TREATMENT AND OTHER WASTE HANDLING ACTIVITIES
}

\author{
Lennart Mårtensson ${ }^{1}$ \\ Lars Thörneby ${ }^{2,3}$ \\ Staffan Bergström ${ }^{1,3}$ \\ Diauddin Nammari, ${ }^{2,3}$ \\ Lennart Mathiasson ${ }^{3}$ \\ ${ }^{1}$ Kristianstad University, Sweden \\ ${ }^{2}$ Kalmar University, Sweden \\ ${ }^{3}$ Lund University, Sweden
}

\begin{abstract}
Volatile organic compounds (VOC) are typically defined as those predominantly present in the vapour phase in air at ambient temperature. They range in volatility from methane to $\mathrm{n}-\mathrm{C} 16$ above and include all chemical groups - alcohols, ketones, aldehydes, esters, glycol ethers, halogens and hydrocarbons. Many of the VOCs are produced and emitted when organic matter decomposes from microbiological activity. A great number of volatile compounds been identified in the air in the vicinity of landfills. VOCs emitted from landfills pose as health concern and odour annoyance for the neighbourhood. High concentrations of VOCs have also been identified in the working environments at waste handling facilities. Emissions of volatile organics from leachate, and how the treatment system affects the fate of the VOCs have been reported. A variety of different sampling strategies and sampling media can be used to address different monitoring requirements, including adsorption tubes and impingers with a suitable absorption solution. Final analysis of VOCs can be performed with a combination of thermodesorption of adsorption tubes and GC-MS. Model studies of the emission of VOCs from the water surface, at the actual site in ponds or in the laboratory, can be performed in order to facilitate budget calculations using a special designed hood. Results from analysis of leachate before and after treatment procedures, using purge and trap methodology, shows how some identified VOCs such as for example benzene, toluene, xylen and trimethylbenzene are to some extent removed from the liquid.
\end{abstract}

\section{INTRODUCTION}

One of the pollutant emitted when organic matter decompose are volatile organics originating from microbiological activity. Landfill gases are produced during the lifetime 
KALMAR ECO-TECH'03

Bioremediation and Leachate Treatment

KALMAR, SWEDEN, November 25-27, 2003

of a landfill. Gases emitted in high concentrations are methane and carbon dioxide, both known contributors to the global greenhouse effect. In different application methane is known as a biogas and utilised as fuel for vehicles and for heating purposes. Volatile organic compounds (VOC) are typically defined as those predominantly present in the vapour phase in air at ambient temperature. They range in volatility from methane to $\mathrm{n}$ C16 above and include all chemical groups - alcohols, ketones, aldehydes, esters, glycol ethers, halogens and hydrocarbons. The concentration of these vapours in air will vary depending on the nature of activity in the location concerned, weather conditions and source matter. Levels can range from low percent concentrations in stack and vent emissions to low ppt in ultra clean outdoor locations. A great number of volatile compounds been identified in the air in the vicinity of landfills ${ }^{1,2}$. Volatile organic compounds emitted from landfills pose as health concern and odour annoyance for the neghbourhood. High concentrations of volatile organic compounds have been reported in a study of working environmental conditions at waste handling facilities ${ }^{3}$. James and Stack ${ }^{4}$ have reported results about emissions of volatile organics from leachate, and how the treatment system affects the fate of the VOCs.

\section{SAMPLING PROCEDURES}

A variety of different sampling strategies and sampling media have been developed to address different monitoring requirements, including:

- On-line, semi-continuous sampling of air/gas streams for real-time studies -

- Grab sampling into evacuated canisters

- Pumped sampling into containers (canisters, Tedlar ${ }^{\mathrm{TM}}$ bags, etc.)

- Pumped sampling into absorption solutions in impingers

- Pumped sampling into single or multi-bed adsorbent tubes

- Diffusive sampling into adsorbent tubes or cartridges

Model studies of the emission of VOCs from the water surface, at the actual site in ponds or in the laboratory, can be performed in order to facilitate budget calculations using equipment as shown figure 1. Basically an air stream is lead over the surface in the emission hood and vapours are collected using impingers and/or adsorbent tubes (i.e. head space method). Another way is to purge the liquid with a gas and collect the volatiles in the outlet in a selective sampling device (i.e. purge and trap method).

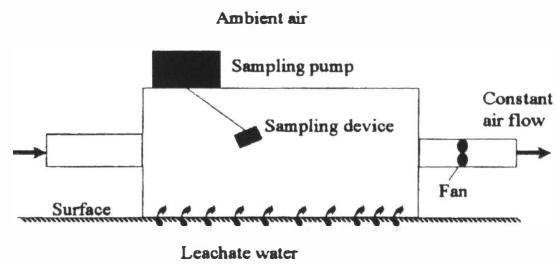

Figure 1. Equipment for headspace sampling of volatile compounds from liquid surfaces. 


\section{ANALYTICAL PROCEDURES}

The best analytical technology for collecting accurate speciated data from the complex matrix of several hundreds of organic chemicals present in air is thermal desorption combined with GC and - where there is a possibility of unknowns - MS detection. Thermal desorption is a high sensitivity alternative to conventional solvent extraction methods. It is a versatile gas extraction process offering significant concentration enhancement and compatibility with all the air sampling methods listed above. A combined TD-GC(-MS) system provides (selective) concentration of trace organic compounds, component separation plus quantitative and qualitative analysis of each individual compound present.

\section{EXPERIMENT}

Leachate water in an impinger flask was purged with nitrogen gas at a flow of $200 \mathrm{ml}$ per minute during 2 minutes. Preconditioned adsorbent tubes, filled with Tenax ${ }^{\mathrm{TM}}$, were placed in the outlet for trapping the vapours. For analysis of VOCs the adsorbent tubes were placed in a thermodesorbent unit coupled to a GC-MS.

In figure 1 is presented a chromatogram from analyses of VOCs from raw leachate water from a municipal solid waste landfill. In the sample different compounds were identified, such as for example benzene, toluene, x-xylen and trimethyl-benzene. In samples collected from other steps in the treatment system at this landfill these substances were found in low quantities or not at all. This indicates how the presence of VOCs is affected by the handling of leachate.

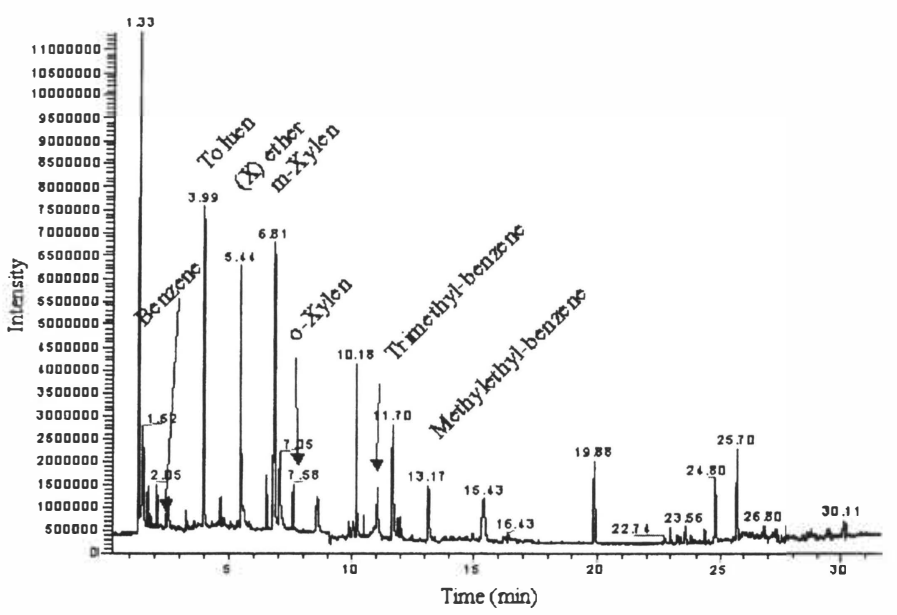

Figure 2. Analyses of VOCs in raw leachate from a MSW landfill. 


\section{REFERENCES}

[1] Ekelund, B., Anderson, E.P., Walkers, B.L., and Burrows, D.B. (1998)

Characterization of landfill gas compostion at the Fresh Kills municipal solid-waste landfill. Environ. Sci Technol. 32:2233-2237.

DOI: https://doi.org/10.1021/es980004s

[2] Zou, S.C, Lee, S.C., Chan, C.Y, Ho, K.F., Wang, X.M., Chan, L.Y. and Zhang, Z.X. (2003) Characterization of ambient volatile organic compounds at a landfill site in Guangzhou, South China. Chemosphere 51:1015-1022.

DOI: https://doi.org/10.1016/S0045-6535(03)00004-3

[3] Poulsen, O.M, Breum, N.O., Ebbehøj, N., HansenÅ.E., Ivens, U.I., van Lelieveld, D.Malmros, P., Mathiasen, L., Nielsen, B.H., Møller Nielsen, E., Schibye, B., Skov, T., Stenback, E.I.. and Wilkins. (1995) Sorting and recycling of domestic waste.

Review of occupational health problems and their possible causes. The Science of the Total Environment 168:35-56. DOI: https://doi.org/10.1016/0048-9697(95)04521-2

[4] James, K.J. and Stack, M.A. (1997) The impact of leachate collection on air quality in landfills. Chemosphere 34:1713-1721.

DOI: https://doi.org/10.1016/S0045-6535(97)00028-3 